\title{
EFFECT OF TUNNEL ON THE RESISTANCE OF HIGH-SPEED PLANING CRAFT
}

\section{Anantha Subramanian ${ }^{1}$ and P.V.V. Subramanyam ${ }^{2}$}

${ }^{1}$ Associate Professor, Department of Ocean Engineering, Indian Institute of Technology Madras, Chennai- 60036, India. Ph. +91-44-22574812, Email: subru@iitm.ac.in

${ }^{2}$ Research Scholar, Department of Ocean Engineering, Indian Institute of Technology Madras, Chennai- 60036, India. Email: subbupvv@,rediffmail.com

\begin{abstract}
Tunnels are provided in ship hulls to accommodate propellers under reduced draught conditions, thereby avoiding reduction of propeller diameter and consequent loss of efficiency. In this work the hydrodynamic effect of propeller tunnels in high speed craft, by way of modified resistance and pressure distribution, are studied both numerically using CFD, and experimentally using geometrically scaled models. The experimental study has been conducted on the model of a single hard chine hull form designed for specific length to displacement ratio. The parametric study considers two other draught conditions. In order to bring out pressure influences, CFD based simulations have been carried out. It is noted that the pressure distributions are altered around the tunnel region and, for an investigated case of tunnel area ratio, there is consistent reduction of resistance for all the three draught conditions tested. The study also compares the merits of the modified Froude extrapolation method, after correction for flow velocity due to pressure development in the hull zone, with the classical Savitsky's method for planing hulls. The qualitative aspects with respect to pressure distribution are brought out in the CFD based studies and the pressure predictions do show consistency with obtained experimental data.
\end{abstract}

Keywords: High speed planing craft, Tunnels, Resistance, Extrapolation methods, Pressure distribution, CFD Studies.

\section{NOMENCLATURE:}

k Turbulent kinetic energy

L Length on waterline

LCG Longitudinal centre of gravity

$A_{P} \quad$ Projected area of the planing hull

$\mathrm{C}_{\mathrm{f}} \quad$ Schoenherr turbulent friction coefficient

$\mathrm{V}_{1} \quad$ Average bottom velocity

$\nabla \quad$ Volume of displacement

$\mathrm{F}_{\mathrm{n}} \quad$ Froude number

$\rho \quad$ Mass density of water

$\Delta \quad$ Displacement

$\beta \quad$ Deadrise angle

V Forward speed

b Maximum beam at chine

$\mathrm{D}_{\mathrm{f}} \quad$ Viscous component of drag

a Distance between $\mathrm{D}_{\mathrm{f}}$ and $\mathrm{CG}$

c Distance between N and CG

$\mathrm{N}$ Resultant of pressure forces acting normal to bottom

B Buoyancy of the model

$\mathrm{L}_{\mathrm{m}} \quad$ Lift force acting on the mode

P1 - P 14 Pressure transducer locations from 1 to 14

$\mathrm{X} \quad$ Distance of pressure tapping location measured from transom

$\mathrm{Rn} \quad$ Reynolds number $\varepsilon \quad$ Turbulent energy dissipation rate

$\mathrm{T} \quad$ Draught

CG Centre of gravity

$\mathrm{A}_{\mathrm{T}} \quad$ Projected area of the tunnels

$\tau \quad$ Trim angle

$\lambda \quad$ Wetted length to beam ratio

$\mathrm{C}_{\mathrm{v}} \quad$ Coefficient of velocity

$\mathrm{F}_{\mathrm{n} \nabla} \quad$ Volume based Froude number

$\mathrm{T} \quad$ Propeller thrust

VCG Vertical cenre of gravity

$\mathrm{B}_{\mathrm{T}} \quad$ Beam at transom

d Draft of keel at transom

$\mathrm{C}_{\mathrm{p}} \quad$ Centre of pressure

D Total drag

f Distance between $\mathrm{T}$ and CG

$\mathrm{L}_{\mathrm{BP}} \quad$ Length between perpendiculars

$\mathrm{R}_{\mathrm{TM}} \quad$ Total model resistance

$\mathrm{D}_{\mathrm{m}} \quad$ Drag of the model

$\mathrm{p}_{\mathrm{d}} \quad$ Maximum bottom pressure

$\mathrm{W}_{\mathrm{m}} \quad$ Displacement of the model 


\section{Introduction}

Planing crafts are high-speed marine vehicles, with applications ranging from small pleasure boats to large military crafts. Generally, in a properly configured planing hull form, the deadrise angle diminishes from bow towards stern. High-speed planing crafts have hard chine, and may have both longitudinal and transverse steps at intermediate positions over the wetted region. The planing craft is typically run with a small bow-up trim or attack angle.

Because of the constant deadrise angle at the aft, planing crafts often have constraint of space for accommodating propellers. A solution to this problem is to provide propellers on inclined shafts. Another alternative is to provide tunnels (also called "propeller pockets") at the bottom of planing hulls. The enhancement achieved by using a partial tunnel includes reducing the shaft angle, decreasing navigational draft and allowing the propulsion machinery to be moved aft for an appropriate longitudinal centre of gravity location with improved arrangement of machinery space. By using tunnels, reduction of propeller diameter can be avoided. Therefore the provision of tunnels gives the designer freedom not to reduce propeller diameter and therefore efficiency. The question is how beneficial are tunnels, and if so, is there any trade offs in terms of other characteristics.

In more recent years Computational Fluid Dynamics (CFD) codes have been applied to modelling ship flows. The increase is due to advances in computational methods together with the increase in performance and affordability of computers. The increased use of CFD has established commercial CFD as credible design tools for solving practical flow problems such as the highly complex problem of flow past ship hulls. Today CFD does give qualitative information to decide the relative merits such as flow alteration in and around the ship hull due to the geometry of the tunnel.

\section{Motivation}

Since the early 1960's several different planing hull forms have been systematically investigated for obtaining total resistance. Blount and Clement (1963) presented a simplified prediction method for the estimation of planing hull resistance. Savitsky (1964) presented a performance prediction method using the empirical equations for lift, drag, wetted area and centre of pressure. The method is still used as a first estimate method for planing hull resistance. Harbaugh and Blount (1973) presented model resistance and self propulsion data from experiments modified for shallow and deep tunnels and with propellers of different diameters. They observed that the deep tunnelled hull in combination with propellers of large diameter and the smallest permissible tip clearance compare well performance-wise to the hull with no tunnels. Koelbel (1979) studied the effect of tunnels and observed the changes in drag and propeller performance. Blount (1997) has given guidelines for the design of partial propeller tunnels and relative placement of propellers to achieve exceptional vessel performance. Experimental and CFD studies have been carried out by Thornhill et al (2003) to measure the drag as well as pressure distribution on the planing vessel at steady speed through calm water. The lack of rigorous qualitative analysis of flow, pressure and resistance effects due to the presence of tunnels is the major motivation for the present study.

\section{Methodology}

The major difference in the method of extrapolation of resistance from model to prototype for planing hulls and displacement hulls, is essentially due to the different velocity conditions near the hull. In a planing hull, due to the dynamic lift condition, there is alteration of trim as well as draught in running condition. Savitsky (1964) proposed the use of average bottom velocity instead of the free stream velocity in the calculations for frictional resistance component. The scheme predicted the performance of a prismatic planing hull based on the empirical equations for lift, drag, wetted area, centre of pressure, and porpoising limits as a function of speed, trim angle, deadrise angle and loading. It is an iterative method based on choosing trim angles, which are then used in empirical equations to obtain 
values for lift and equilibrium moment in trim. The method progresses till equilibrium of body forces are obtained. The forces acing on the planing hull is shown in Fig. 1.

The planing hull is said to be in equilibrium when it satisfies the following equation

$$
\Delta\left\{\frac{[1-\sin \tau \sin (\tau+\varepsilon)] c}{\cos \tau}-f \sin \tau\right\}+D_{f}(a-f)=0
$$

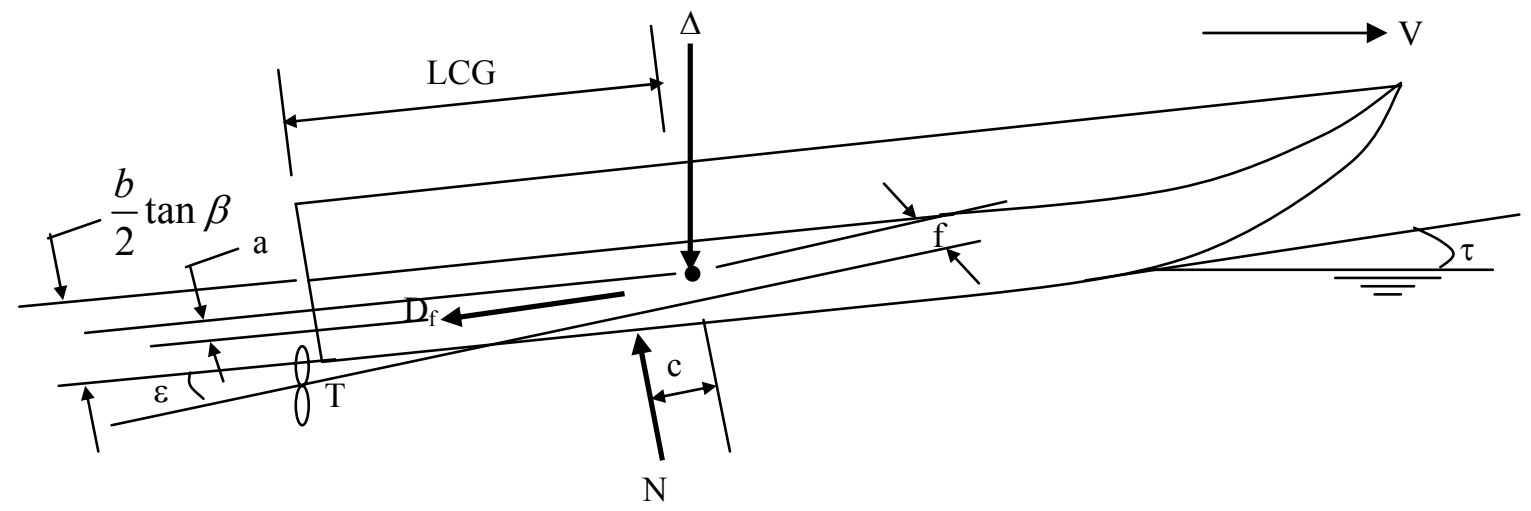

Fig. 1 Forces acting on the planing hull

Where

$$
\begin{array}{ll}
c=L C G-C_{p} \lambda b & a=V C G-(b / 4) \tan \beta \\
C_{p}=0.75-\frac{1}{5.21 C_{v}^{2} / \lambda^{2}+2.39} & D_{f}=\frac{C_{f} \rho V_{1}^{2}\left(\lambda b^{2}\right)}{2 \cos \tau} \\
\frac{0.242}{\sqrt{C_{f}}}=\log _{10}\left(R n \times C_{f}\right) & \\
V_{1}=V\left(1-\frac{2 p_{d}}{\rho V^{2}}\right)^{1 / 2} & \\
p_{d}=\frac{\Delta}{\lambda b^{2} \cos \tau}=\frac{0.0120 \tau^{1.1} V^{2} \rho}{2 \lambda^{1 / 2} \cos \tau} &
\end{array}
$$

It may be noted that the above scheme can only be iteratively used, ensuring that the first equation is satisfied by iterative choice of values of trim angle. Once the correct trim angle is obtained, the hydrodynamic drag is obtained from

$$
D=\Delta \tan \tau+\frac{D_{f}}{\cos \tau}
$$

\subsection{The modified Froude extrapolation (MFE) method}

This method is used for planing craft for extrapolating experimental data from model to obtain prototype values. The lift $L_{m}$, is calculated on the basis of the following formula based on resolution of lift, drag, weight and buoyancy forces

$$
L_{m}=\left(R_{T M}+\frac{W_{m}}{\tan \tau}-\frac{B}{\tan \tau}\right) \sin \tau
$$

The drag $D_{m}$, is given by 


$$
D_{m}=\frac{\left(R_{T M}-L_{m} \sin \tau\right)}{\cos \tau}
$$

The resultant normal force $N$, is calculated as

$$
N=\left(L_{m} \cos \tau-D_{m} \sin \tau\right)
$$

The maximum bottom pressure $P_{d}$, is $p_{d}=\frac{N}{\frac{L}{2} \times b \times \cos \tau}$

The resultant velocity $V_{l}$, using Bernoulli's equation, is obtained as

$$
V_{1}=\sqrt{V^{2}-\frac{2 p_{d}}{\rho}}
$$

The frictional resistance is calculated from the ITTC ' 57 correlation line using the above modified velocity and appropriate wetted length. Hence in the modified extrapolation scheme, the modified velocity is associated with the calculation of $C_{T M}$ and the subsequent extrapolation to prototype values.

\section{Numerical Studies}

\subsection{Computational method for pressure and resistance}

The objective of the CFD simulations was to obtain pressure distributions. These were later validated by comparison with experimental data. The study was also extended to obtaining the modified pressures due to the existence of the tunnels in the aft region. CFD simulations can overcome the shortcomings of the experiments to measure the pressure distribution on the bottom of the hull. Hence the simulations of the flow field around the high speed planing hull model with and without tunnels for $\mathrm{L} / \nabla^{1 / 3}=6.5$ were performed in order to find out the hull pressure distribution. For this purpose, the flow problem was solved by continuity and momentum equation around the body in the domain of interest. The velocity components are governed by momentum equations and this requires determination of pressure. The procedure is based on SIMPLE (Semi-Implicit Method for Pressure Linked Equations) algorithm. In principle, a pressure field is initially guessed and the corresponding velocity field is computed using momentum equation. On substituting the velocity field in the continuity equation, and based on conservation of mass, pressure correction is obtained by solving the continuity equation written in terms of pressure correction. Using the corrected pressure, the above steps are repeated till the converged solution is obtained.

The CFD software FLUENT Version 6.0.20 is used for the present computations. The finite volume method is used for discretising the governing equations and employing the Cartesian coordinate system for mapping the physical plane to the computational domain. The computational models chosen are shown in Fig. 2. All CFD studies performed here are based on model scale in order to directly compare with model based results. The computations are carried out over a model speed range from 2.58 to $4.24 \mathrm{~m} / \mathrm{s}$ (Froude no. 0.55 to 1.03 ). Using a modelling pre-processor GAMBIT 2.0, the geometry is generated with 3-D unstruc- tured mesh with tetrahedral elements. Unstructured grids have flexibility to match with the surface of the complex geometries of the hull surface.

The fluid domain is shown in Fig. 3 and the domain including the mesh with and without tunnel is shown in Fig. 4. Grid independence studies were carried out by increasing the degree of fineness of the mesh to obtain optimum computational grid for accuracy. Assuming steady flow field, the computations apply measured velocity at the inlet and outlet as boundary conditions. Symmetry 
boundary condition is applied at the central surface and a solid boundary condition with slip is enforced to the top of the domain and a solid wall with no slip condition is prescribed for the hull surface, side and bottom. (See Fig. 5) A segregated solver is used with the standard k- $\varepsilon$ turbulence model. Convergence is obtained when the sum of the residual errors for the pressure, velocity and dissipation of kinetic energy is less than $10^{-4}$.
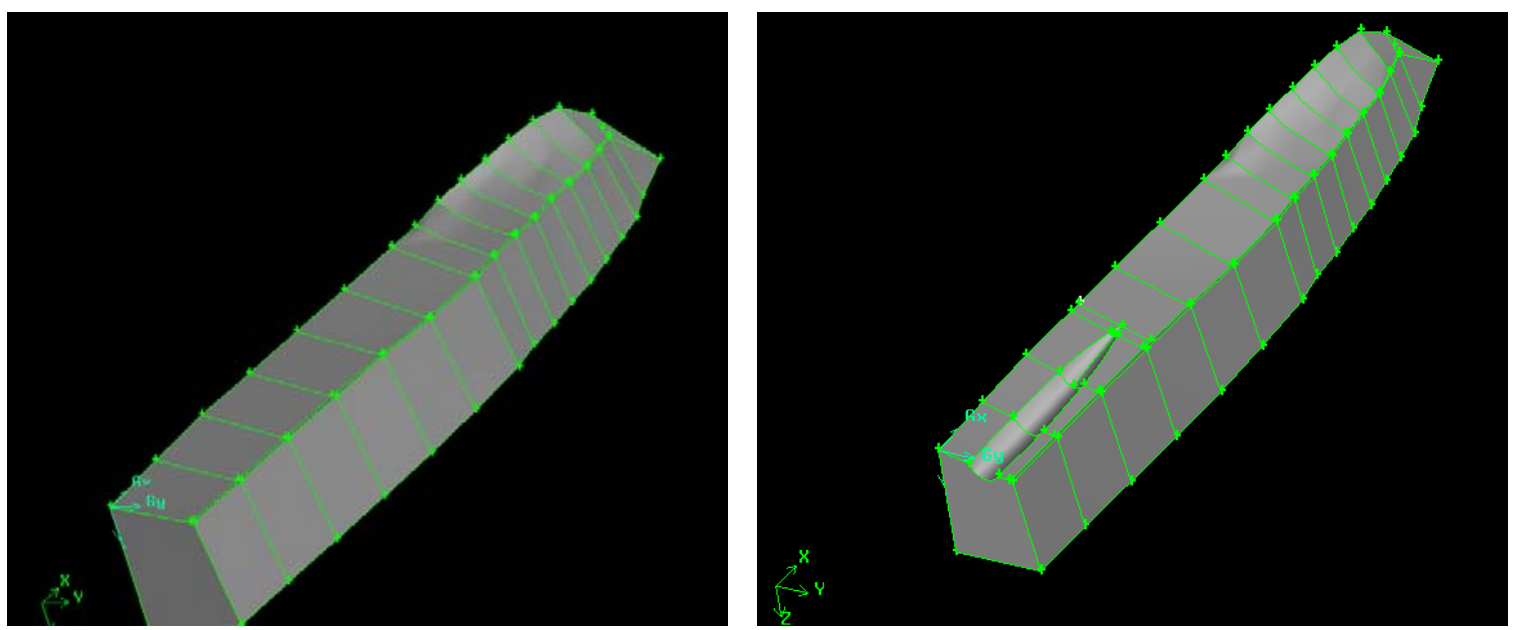

Fig. 2 Planing hull models (a) without tunnel (b) with tunnel using pre-processor GAMBIT 2.0

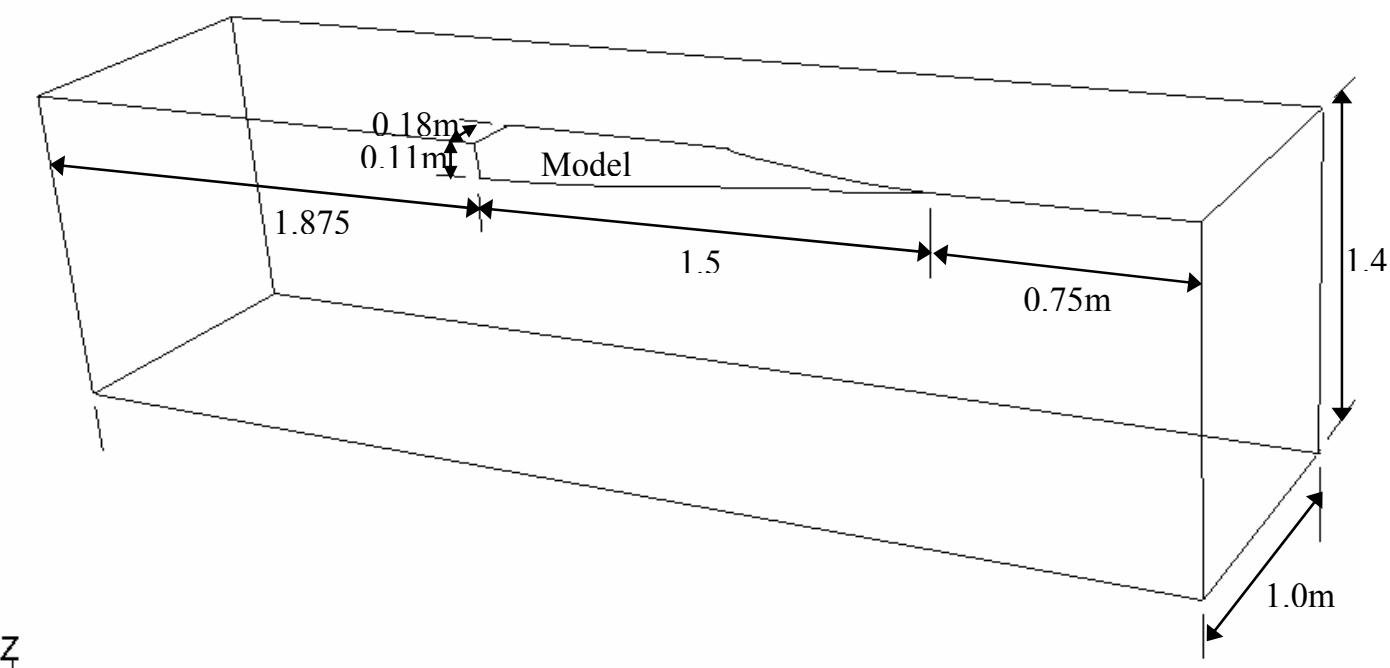

Fig. 3 Planing hull models flow domain

\section{Experimental Investigation}

\subsection{Choice of models and experiments}

A high speed planing hull form of single hard chine type and designed for speed of 35 knots (corresponding to Froude number, $F_{n}=1.0$ where $F_{n}=V / \sqrt{ }(g L)$ was selected. The form is characterized by a fairly constant deadrise angle over the after half of the vessel. The model was 
fabricated in glass-reinforced plastic (GRP) to a scale of 1:20. The model was modified with special bottom inserts which could be removed or filled to represent tunnel shape or 'no tunnel' condition respectively. The details of the hull and tunnels are shown in Tables1 and 2.
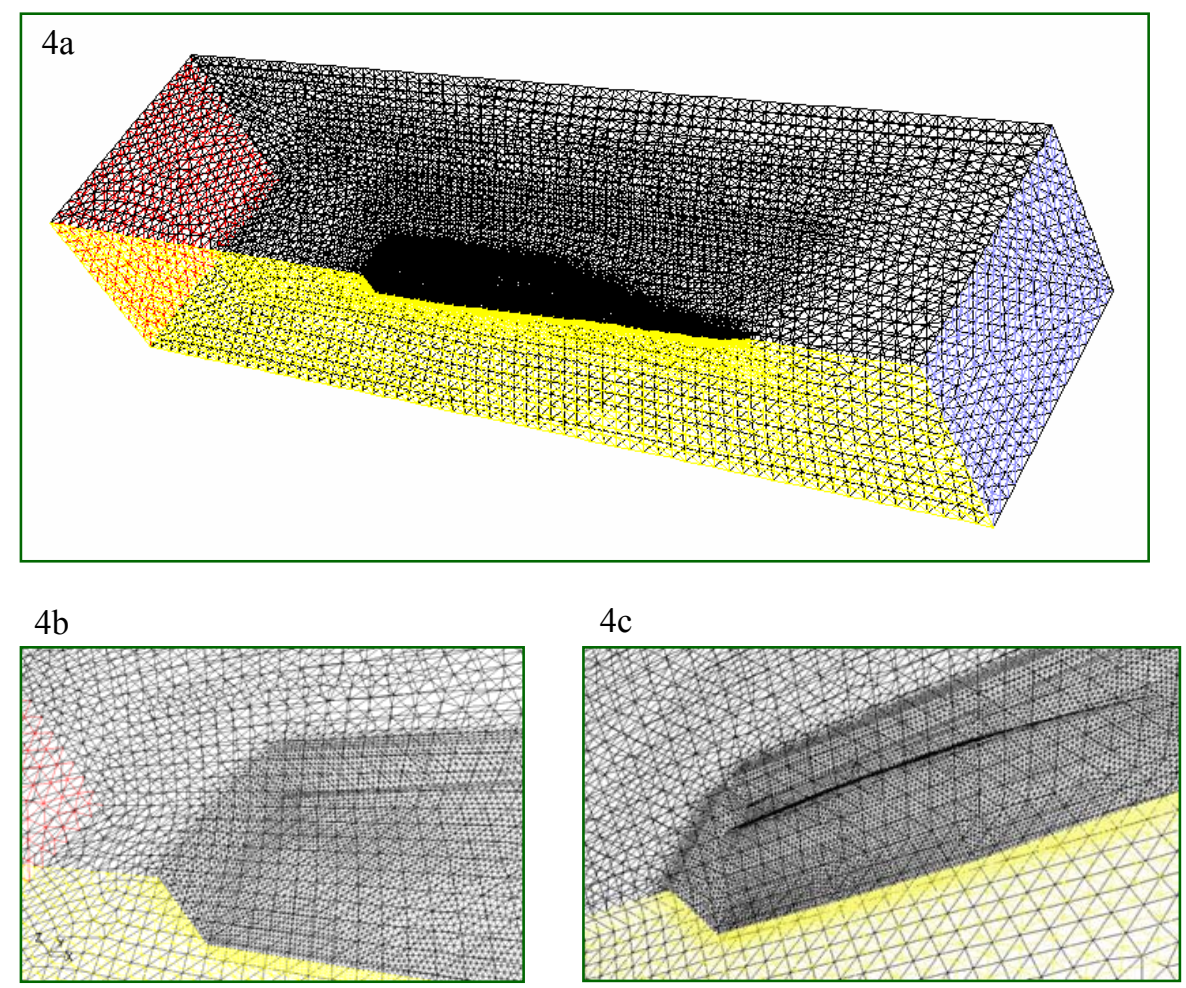

Fig. 4 (a) Domain with mesh and zoomed view near the aft region of the planing hull (b) Without tunnel (c) With tunnel

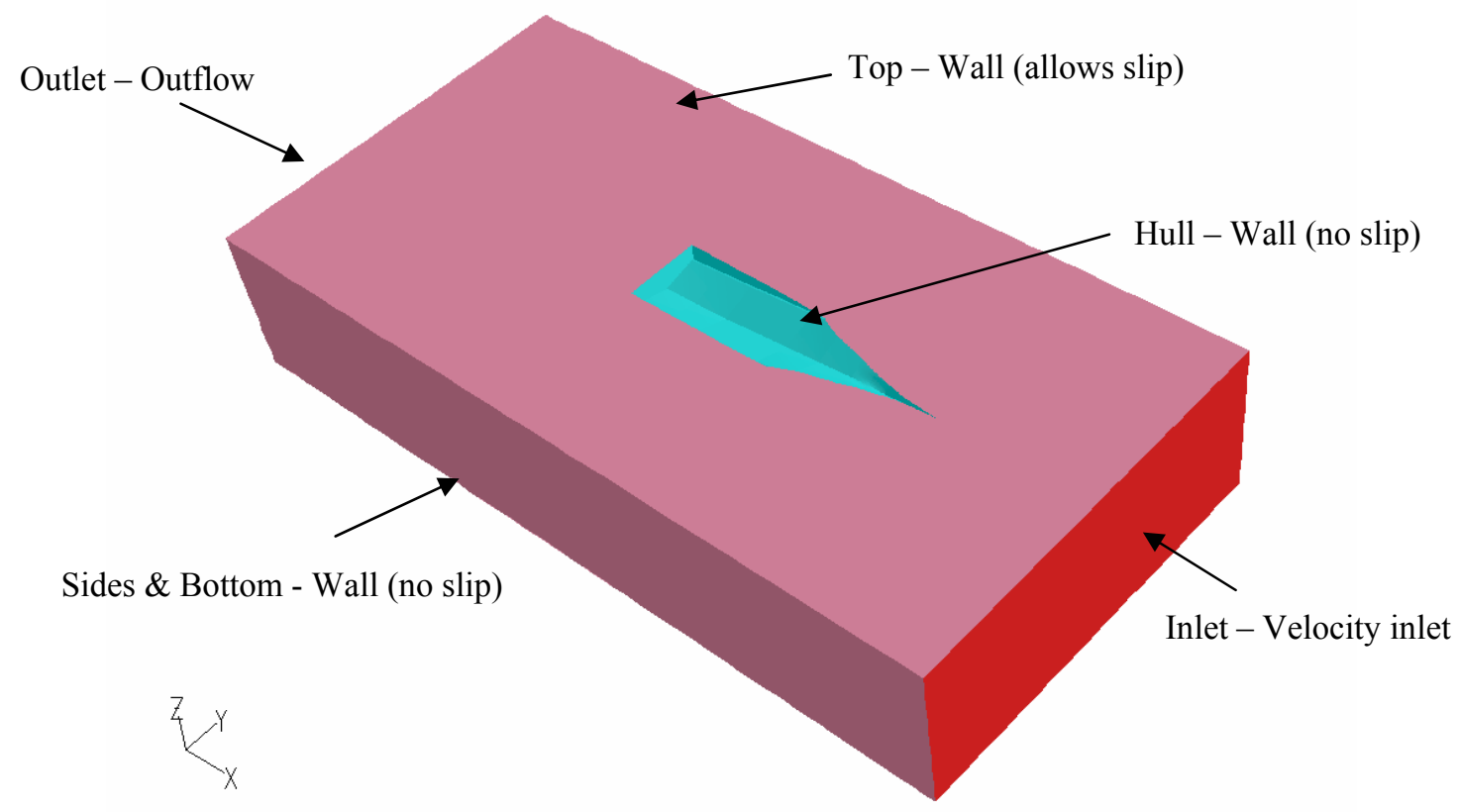

Fig. 5 Boundary conditions 
Table 1 Main particulars of the prototype

\begin{tabular}{|l|c|}
\hline \multicolumn{1}{|c|}{ Particulars } & Prototype \\
\hline Length overall, $(\mathrm{LOA}), \mathrm{m}$ & 37.8 \\
\hline Beam at transom $\left(\mathrm{B}_{\mathrm{T}}\right), \mathrm{m}$ & 7 \\
\hline Beam max. at chine $(\mathrm{b}), \mathrm{m}$ & 7.1 \\
\hline Depth $(\mathrm{D}), \mathrm{m}$ & 5.36 \\
\hline $\mathrm{b} / \mathrm{T}$ & 4.7 \\
\hline $\mathrm{L} / \mathrm{b}$ & 4.68 \\
\hline Deadrise at transom $\left(\beta_{\mathrm{T}}\right), \mathrm{deg}$. & 14 \\
\hline Deadrise at midsection $(\beta), \mathrm{deg}$. & 20 \\
\hline Design speed, knots & 35 \\
\hline Model scale & 20 \\
\hline Volume of displacement $(\nabla), \mathrm{m}^{3}$ & $150 / 142^{*}$ \\
\hline Length on waterline, $(\mathrm{L}), \mathrm{m}$ & $34.4 / 34.4$ \\
\hline Wetted surface area, $(\mathrm{S}), \mathrm{m}^{2}$ & $192 / 193^{*}$ \\
\hline LCG from transom, $\mathrm{m}$ & $12.88 / 13.5^{*}$ \\
\hline
\end{tabular}

* Values with and without tunnels at $1.5 \mathrm{~m}$ draught

The body plan view is shown in Fig. 6. Fig. 7 shows the photograph of the model with tunnels. The tests were performed at three different draught conditions $\left(\mathrm{L} / \nabla^{1 / 3}\right.$ ratios of $6.8,6.5$ and 6.0 corresponding to draught of $1.3 \mathrm{~m}, 1.5 \mathrm{~m}$ and $1.7 \mathrm{~m}$ ) to firmly establish the trend of drag component with and without tunnel influence. The model was designed with a full featured tunnel with $\mathrm{At} / \mathrm{Ap}=0.12$ (i.e., tunnel area ratio which is defined as projected area of tunnels to projected water plane area of hull). The towing carriage fixture permitted the natural heave and trim of the model during steady speed runs.

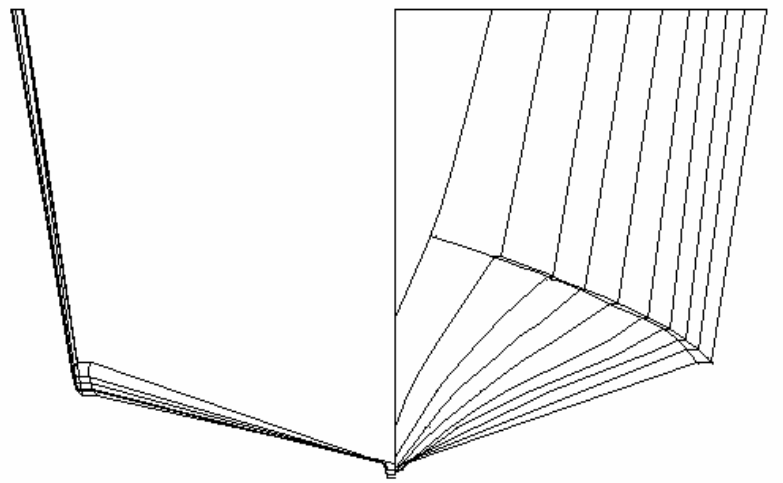

Fig. 6 Bodyplan of planing hull model

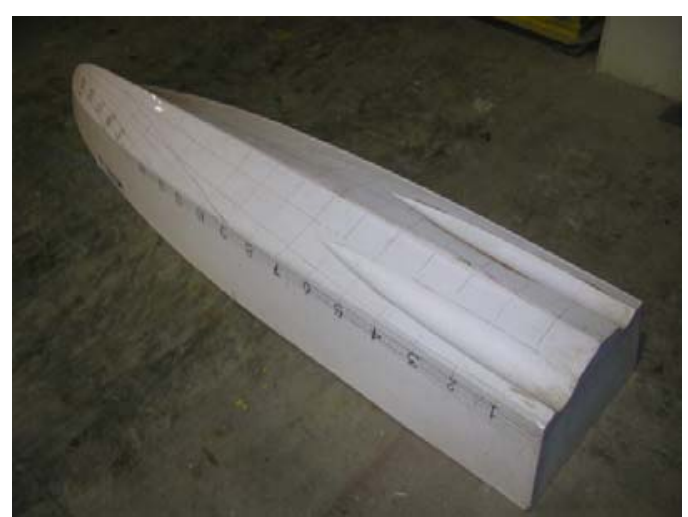

Fig. 7 Photograph of planing hull model

Table 2 Particulars of the tunnel

\begin{tabular}{|l|c|}
\hline \multicolumn{1}{|c|}{ Particulars of Tunnel } & Prototype \\
\hline Propeller immersion, \% & 33 \\
\hline $\mathrm{A}_{\mathrm{T}} / \mathrm{A}_{\mathrm{P}}$ & 0.12 \\
\hline $\mathrm{L}_{\mathrm{T}} / \mathrm{L}_{\mathrm{P}}$ & 0.319 \\
\hline Projected area, $\mathrm{m}^{2}$ & 24.4 \\
\hline Length, $\mathrm{m}$ & 11 \\
\hline Width at transom, $\mathrm{m}$ & 1.3 \\
\hline Width near propeller region, $\mathrm{m}$ & 1.46 \\
\hline Depth near propeller region, $\mathrm{m}$ & 0.48 \\
\hline
\end{tabular}




\subsection{Test facility and set up}

The towing experiments were carried out in a tank of dimensions $82 \mathrm{~m} \times 3.2 \mathrm{~m} \times 2.8 \mathrm{~m}$ at IIT Madras, India. The maximum carriage speed is $5 \mathrm{~m} / \mathrm{s}$. Drag measurements were made using an electronic dynamometer and the trim and C.G. rise were recorded using fore and aft trim indicators. For pressure measurements, 0.2 bar capacity strain gauge based underwater pressure transducers were used. Carrier frequency amplifiers combined with data logger (HP Bench Link) were used for data acquisition. The test setup for the resistance measurement and pressure measurements is shown in Fig. 8. For the pressure measurement, the tapping locations are shown in Fig. 9.

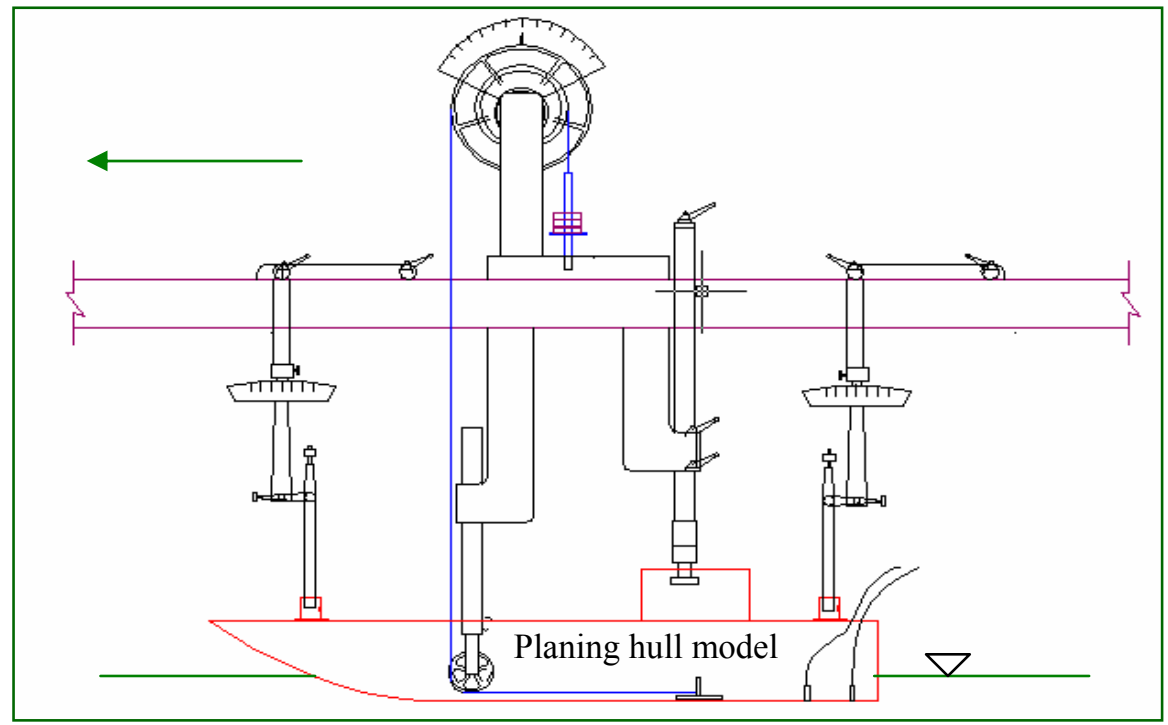

Fig. 8 Experimental set-up of planing hull model for resistance and pressure measurement tests

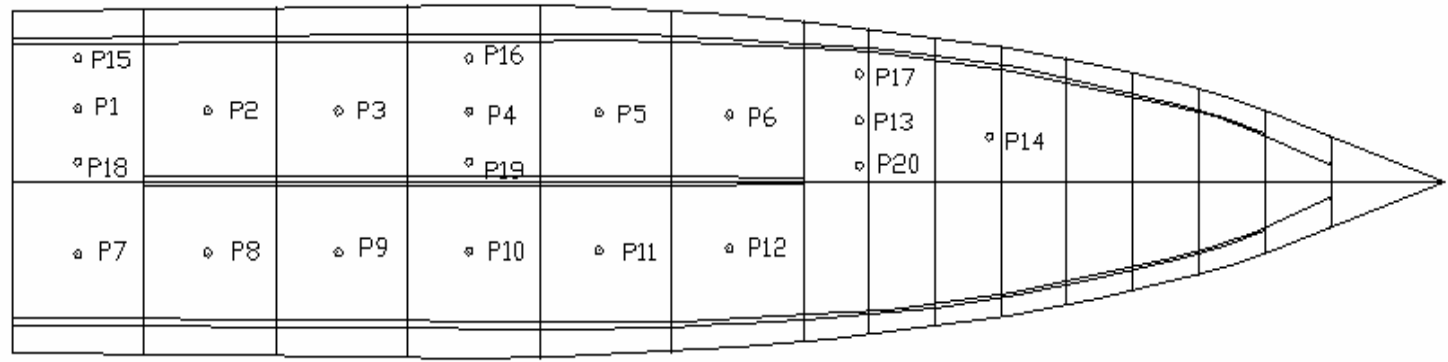

Fig. 9 Location of pressure tappings in planing hull model

\subsection{Experimental Procedure and extrapolation to prototype}

The planing hull model was towed with constant forward speed in calm water. The model was run at different speeds ranging from model speed of $2.30 \mathrm{~m} / \mathrm{s}$ (prototype speed $=20 \mathrm{knots} ; \mathrm{F}_{\mathrm{n}}=0.55$ ) to $4.24 \mathrm{~m} / \mathrm{s}$ (prototype speed $=36.84$ knots; $\mathrm{Fn}=1.03$ ). The tests were conducted for different $\mathrm{L} / \nabla^{1 / 3}$ of each model with and without tunnels and for the above speed range. The model is free to heave and trim naturally during the steady speed measurement phase. While conducting resistance tests on the planing hull, the dynamic condition water line reading at forward and aft was noted by means of a calibration grid on the side of the model. Afterwards, the wetted surface corresponding to each speed in the entire range of speeds was interpolated between the low speed and the high speed dynamic trim condition waterlines in the tests. Model speed for all runs was selected on the basis of equivalent 
Froude number identity with prototype. For the total pressure acting on the bottom of the flat bottom hull model, pressures were measured at a point of $0.25 \mathrm{~B}$ (where $\mathrm{B}$ is the breadth of the model) from the centre line of the model. Typical sampling interval of 10 milliseconds was used for acquiring data from pressure transducers.

The modified Froude's extrapolation method has been used for extrapolating the model planing hull resistance to prototype values. The main difference arises due to the fact that the velocity for frictional resistance assessment is different from the free stream velocity because of the associated pressure build up in the vicinity of the hull. Also in the case of planing hulls, the dynamic wetted surface during planing must be recorded carefully. Therefore the component of viscous resistance is obtained using the modified velocity and the residuary resistance term is then extrapolated from model scale to prototype values. These values have been compared with Savitsky's scheme.

\section{Results and Discussion}

\subsection{Resistance results}

For a particular draught condition $\left(\mathrm{T}=1.5 \mathrm{~m}, \mathrm{~L} / \nabla^{1 / 3}=6.5\right)$ the measured trim and C.G. changes of the model due to the effect of the tunnel are brought out in Figs. 10 and 11. At full planing speed $\left(\mathrm{F}_{\mathrm{n} \nabla}>\right.$ 1.5) the trim is more for the case of the vessel without tunnel. It is obvious that with the present tunnel $\left(\mathrm{A}_{\mathrm{T}} / \mathrm{A}_{\mathrm{P}}=0.12\right)$ the flow for the aft is favourably modified to give the ship a reduced (favourable) trim condition. Similarly the centre of gravity rise is reduced in the case of the vessel with tunnel. There is a characteristic drop of centre of gravity in both the cases (i.e. with and without tunnel) at pre-planing speeds.

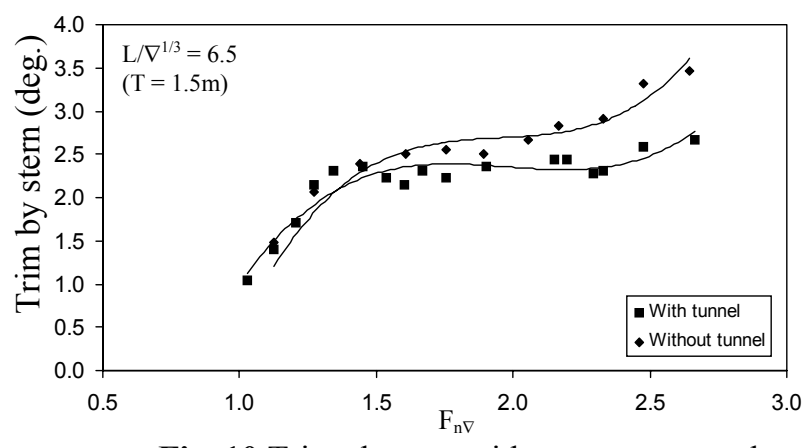

Fig. 10 Trim changes with respect to speed

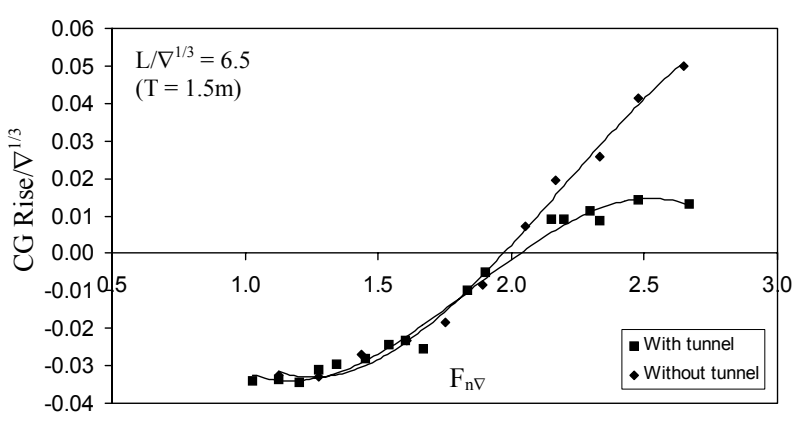

Fig. 11 CG rise with respect to speed

The non-dimensionalized resistance plots are shown in Figs. 12 to 14 . Both the methods of analysis have been used viz., the modified Froude's method and the Savitsky's method. Irrespective of the method used, the resistance with tunnel has always shown reduced value. This trend is in conformity with the beneficial effects as seen in both favourable trim as well as C.G. changes in the cases with and without tunnels.

The comparison of resistance due to the influence of the tunnel is brought out in Fig. 12. To rule out the possibility of erroneous conclusion, the experiments were repeated for the cases of without tunnel and with tunnels for three different draughts $\left(\mathrm{L} / \nabla^{1 / 3}=6.8,6.5,6.0 ; \mathrm{T}=1.3 \mathrm{~m}, 1.5 \mathrm{~m}, 1.7 \mathrm{~m}\right)$ and the curves presented consistently show improved resistance due to the presence of tunnel at all 3 draught conditions.

The results in Figs. 13 and 14 shows that the resistance prediction by Savitsky scheme gives very close values with the experimental results. Comparisons are reasonable up to $F_{n \nabla}=1.9$. 
V. A. Subramanian, P.V.V. Subramanyam / Journal of Naval Architecture and Marine Engineering 1(2005) 1-14
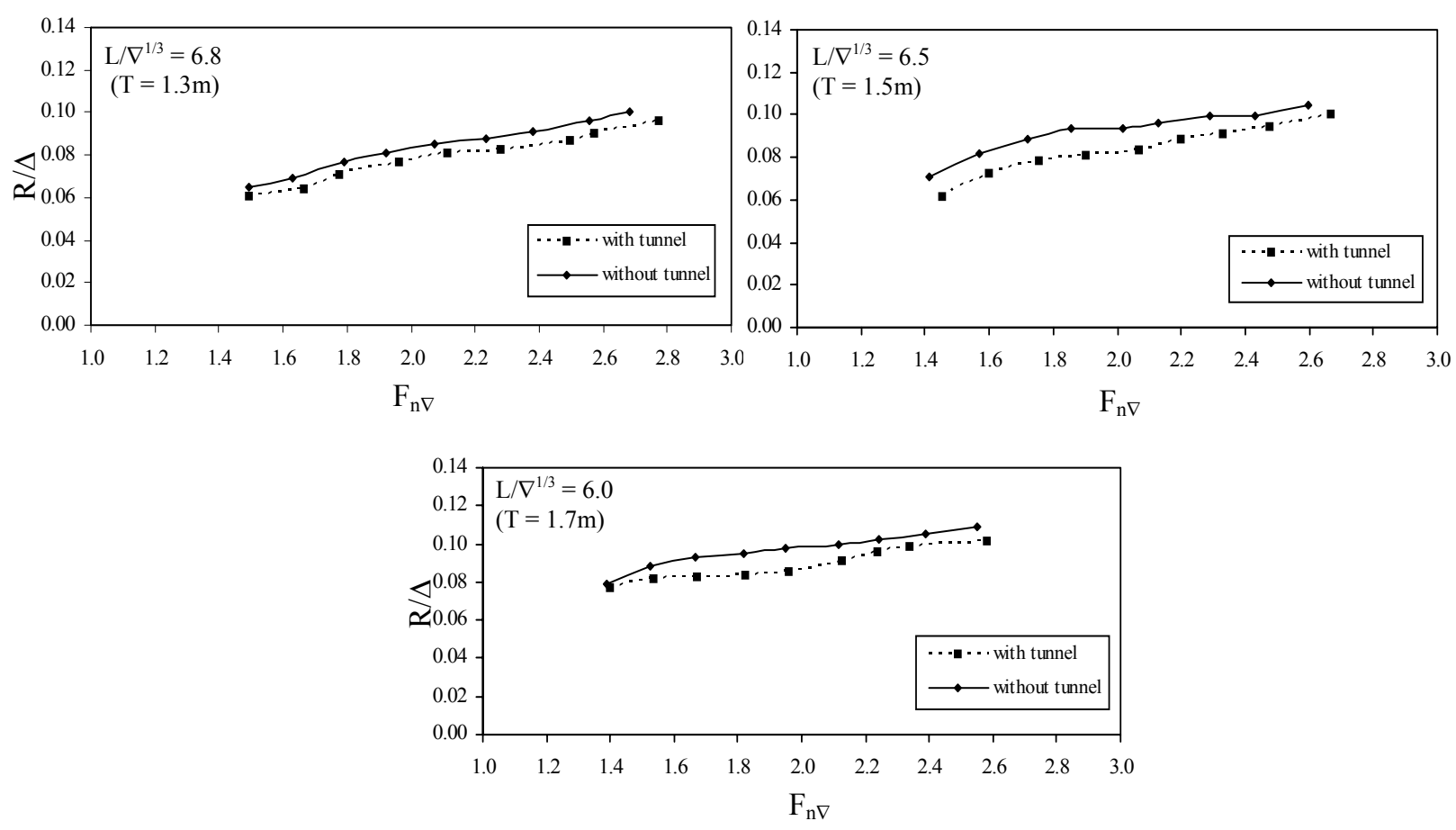

Fig. 12 Resistance with and without tunnels at different draughts

(Modified Froude extrapolation)

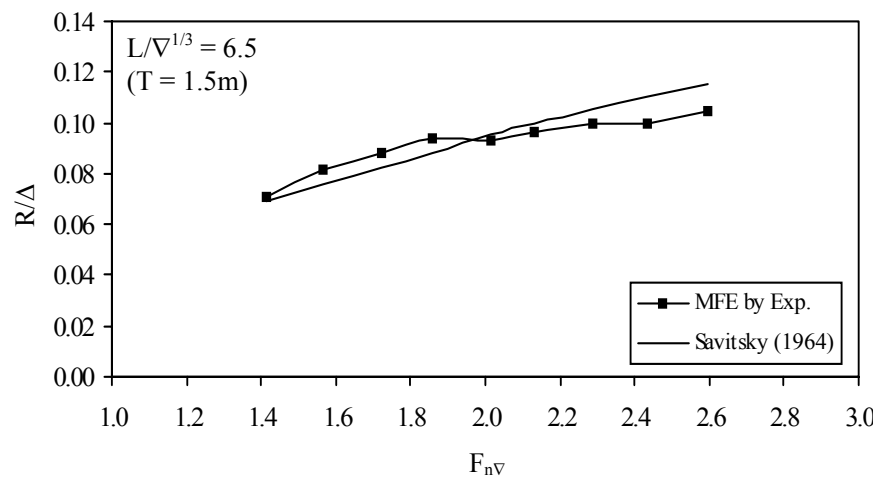

Fig. 13 Resistance without tunnel

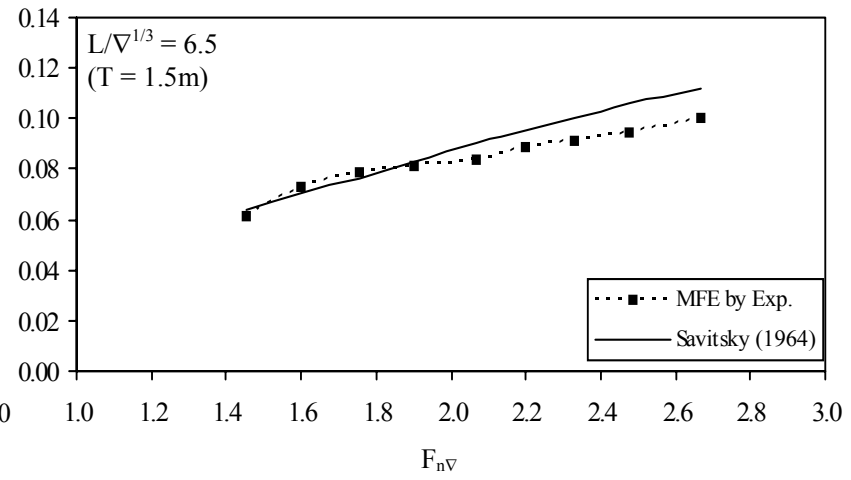

Fig. 14 Resistance with tunnel

It is very evident that the tunnel helps improve resistance. In this particular case the tunnel has been designed with smooth streamlined forward entry. The tunnel depth increases gradually and linearly towards the aft. Hence discontinuity due to tunnel is minimal.

\subsection{Pressure measurements and comparison}

The objective of pressure measurements was to obtain the distribution of pressure in the planing condition and to validate CFD based measurements by comparison. For this purpose the pressure measurements were confined to the case without tunnel. Pressure plots are shown in Figs. 15 and 16. Each curve represents the pressure measurement at a particular location. The pressures measured at the forward most point of contact with water i.e., the spray root region, shows the highest growth of pressure with speed. This pressure vs. velocity curve has the highest gradient. Pressure at mid aft region is consistently high and the pressure vs. velocity gradient is mild. Pressures measured at other points lie between the bandwidth of these points. After the transition to full planing mode, the 
pressures are concentrated maximum at the spray root region and are high at the mid-aft region. Further towards aft, the pressures diminish.

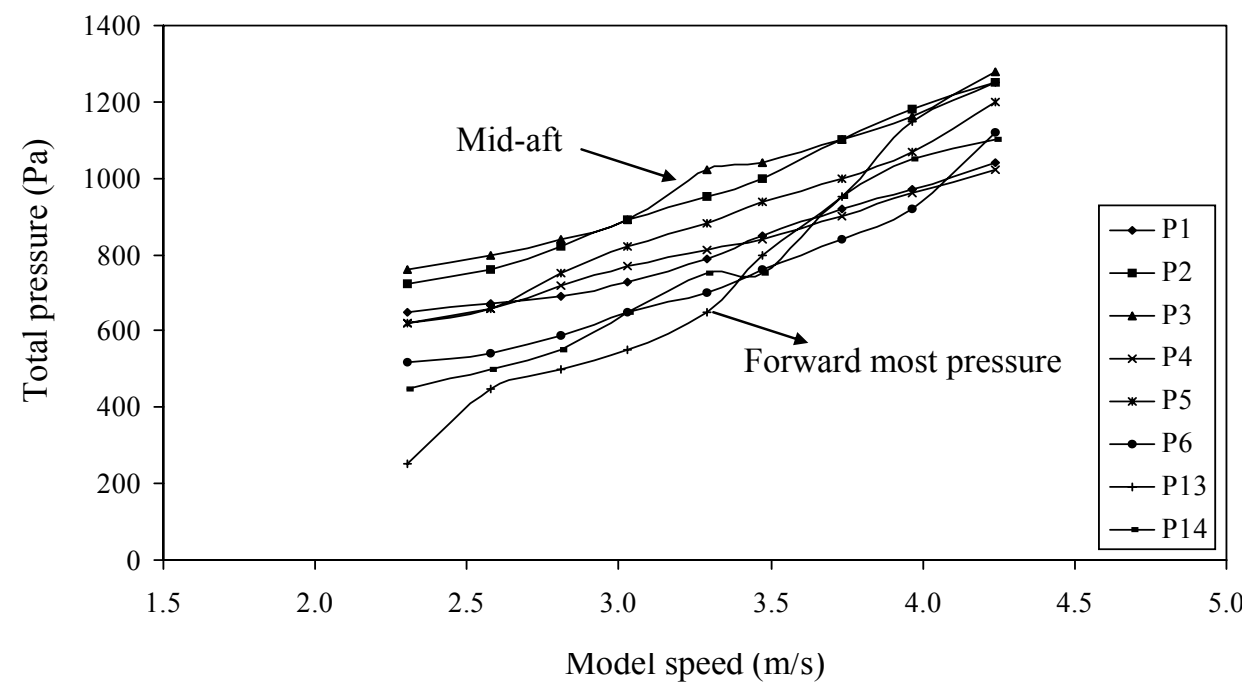

Fig. 15 Total pressure for various model speeds at different locations

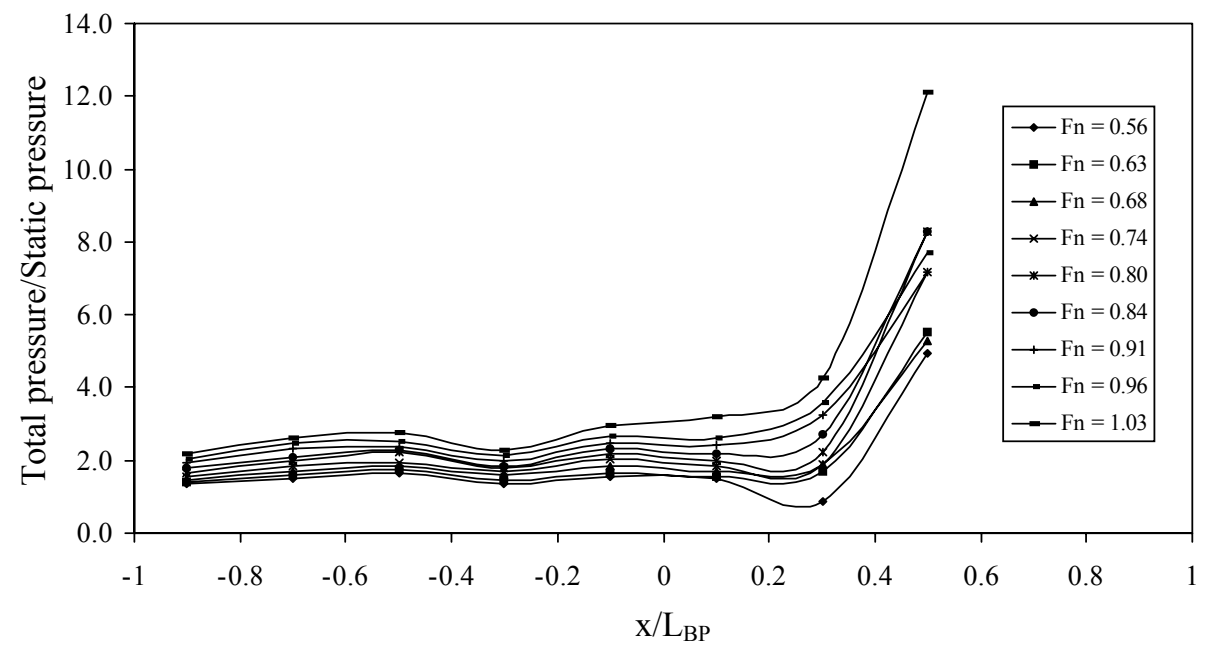

Fig. 16 Non-dimensional pressure along the length of the planing hull model without tunnel

The spatial pressure distribution is shown in Fig. 16. This brings out the consistent concentration of pressure at the spray root region and immediately near it. Further behind this point, the pressures are nearly constant and much less. The CFD based contours of bottom pressure distributions are shown in Figs. 17 and 18. It may be noted that by the choice of coarser pressure range, the contour plots would depict a simpler pressure distribution pattern in the projected hull area with the characteristic fall of pressure from the spray root region at the bow towards the aft. The pressure re-distribution due to the tunnel effect is shown in Fig. 19. The pressure patterns are thus brought out. The CFD based assessment of resistance in the two cases viz., with and without tunnel are shown in Fig. 20. From the experimental study it is established that the re-distribution of pressure results in a favourable trim of the hull resulting in reduced resistance for the case of, with tunnel. The experimentally measured pressures are compared with corresponding values obtained from CFD in Fig. 21. 


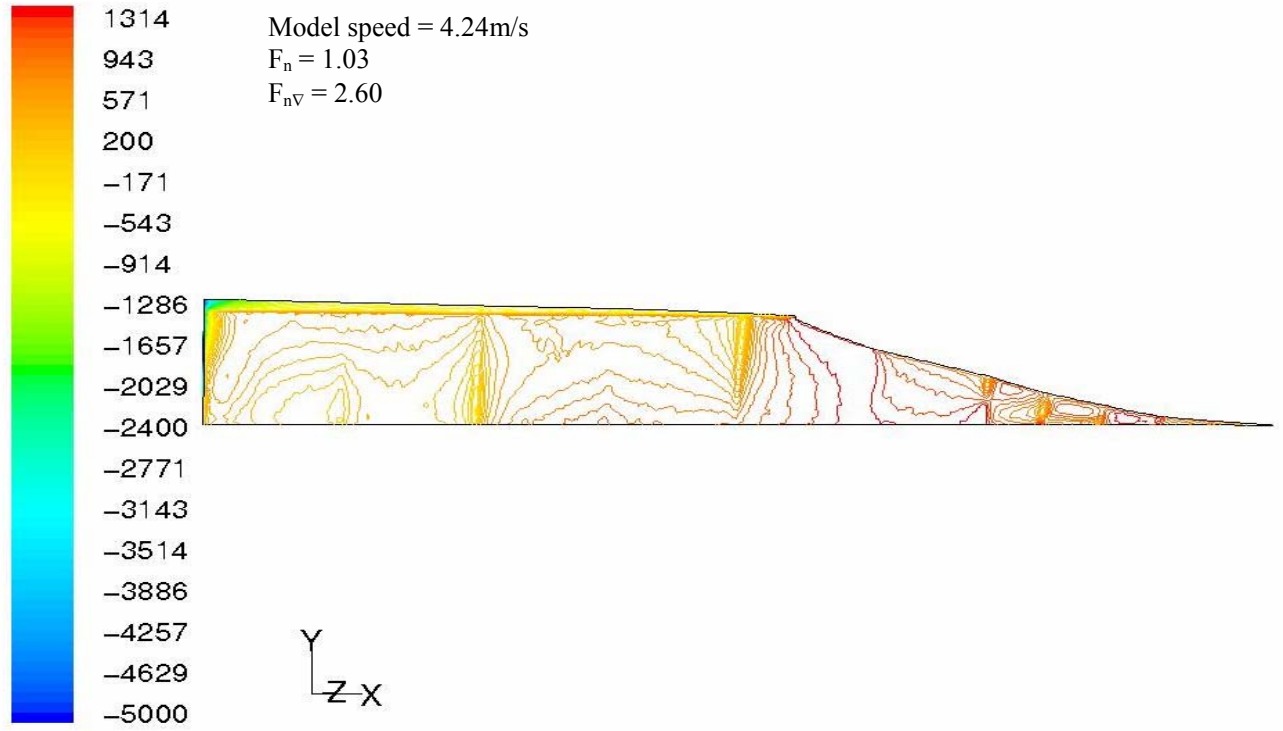

Fig. 17 Contours of total pressure (Pa) of planing hull model without tunnel

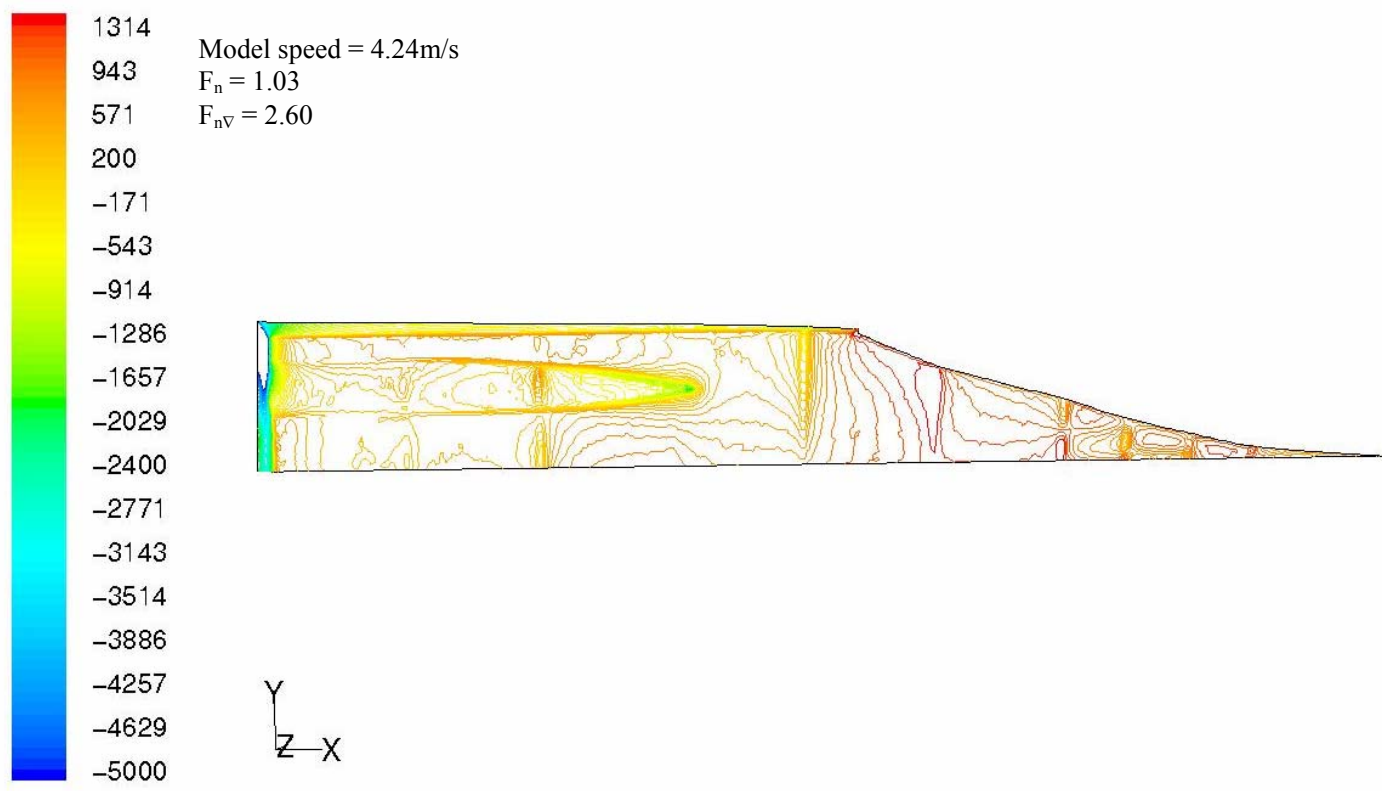

Fig. 18 Contours of total pressure (Pa) of planing hull model with tunnel

\section{Conclusion}

The numerical and experimental investigation on resistance and pressure measurement on planing hulls establish that modified Froude extrapolation results show reasonable match with Savitsky based scheme at the speed range up to $F_{n \nabla}=1.9$. At higher speeds, the divergence of values is higher. There may be a limitation due to the fact that the Savitsky method is generally applicable for prismatic hulls. The present hull has a degree of warp. The conventional modified velocity Froude extrapolation based results show closer match with the Savitsky based scheme at lower speeds. The full featured tunnel 
offers beneficial effect in term of reduced resistance. The CFD simulation of flow with tunnel shows that there is a re-distribution of pressure besides reduction, due to the presence of tunnels. In the tunnel area, there are locations with reduced pressures. Pressure integration in the horizontal direction gives the total drag and the reduction in drag due to the presence of tunnels is re-confirmed in the CFD based studies. The pressure measurements bring out the nature of pressure variation in the underwater hull, with a marked peak at the spray root region. The study directly contributes to the preliminary planing hull design process.
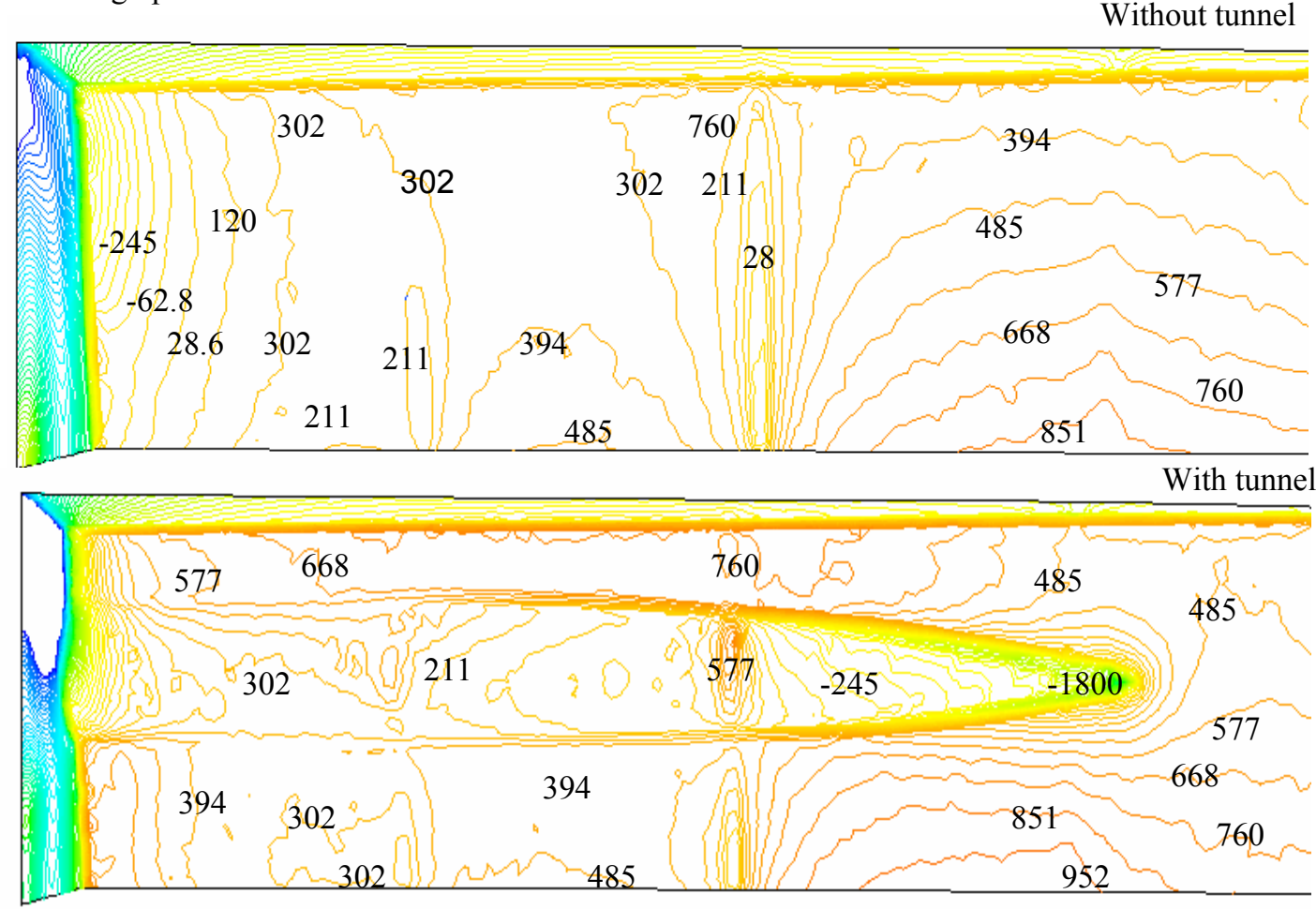

Fig. 19 Contours of total pressure $(\mathrm{Pa})$ in the tunnel region of planing hull model for a model speed of $4.24 \mathrm{~m} / \mathrm{s}$ (Ship speed $=36.84 \mathrm{knots}$ )

\section{References}

Blount D.L. (1997) Design of Propeller Tunnels of High-Speed Craft. FAST'97, Sydney, Australia.

Blount D.L. and E.P. Clement (1963) Resistance tests of a systematic series of planing hull forms. SNAME Transactions, 491-579.

Harbaugh, K. H. and D. L. Blount (1973) An Experimental Study of a High Performance Tunnel Hull Craft, SNAME Spring Meeting, Lake Buena Vista, Florida.

Koelbel Jr., J.G. (1979) Tunnel Hull Designs for U.S. Navy Small Craft, Combatant Craft Engineering, Naval Ship Engineering Center, Norfolk Division.

Savitsky, D. (1964) Hydrodynamic Design of Planing Hulls, Marine Technology, 1(1), 71-95.

Thornhill, E., N. Bose, B. Veitch, and P. Liu (2003) Planing Hull Performance Evaluation Using a General Purpose CFD Code, Proceedings of $24^{\text {th }}$ Symposium on Naval Hydrodynamics. 


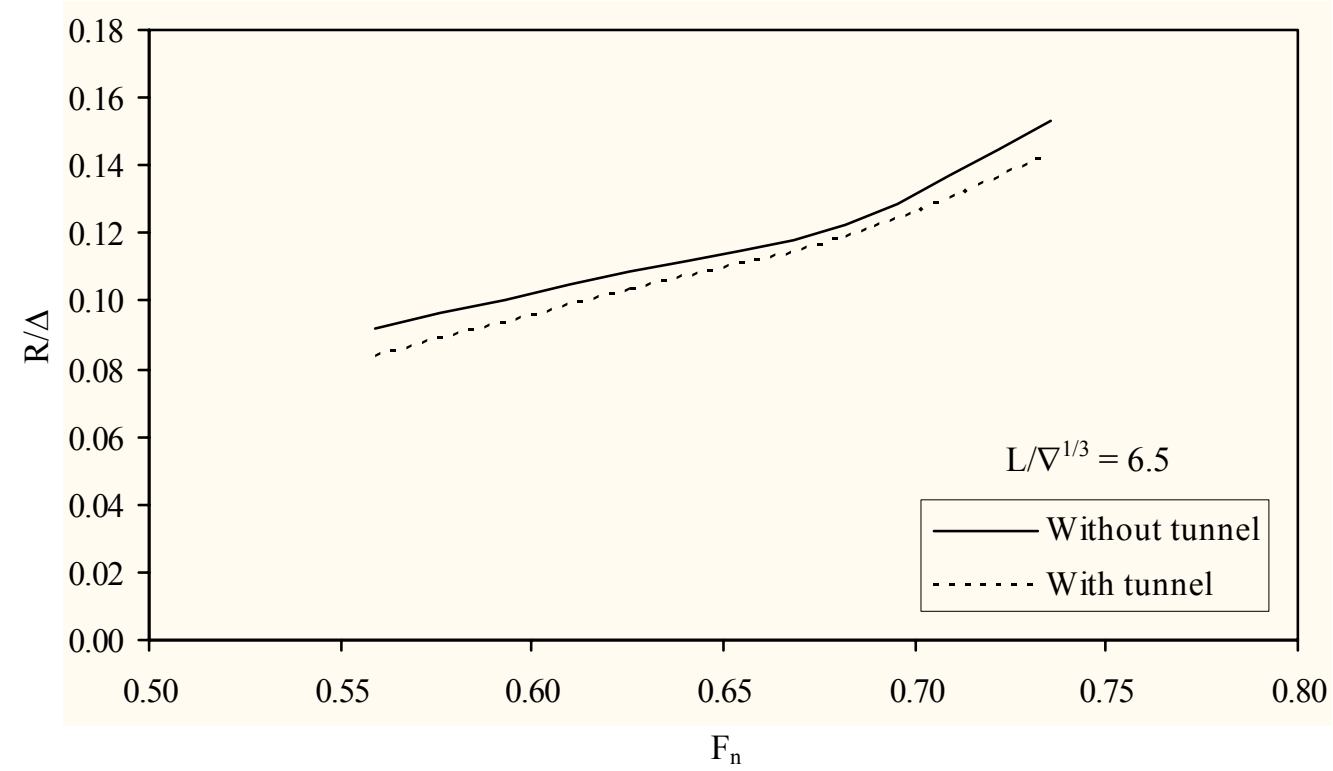

Fig. 20 CFD based comparison of resistance for planing hull with and without tunnel

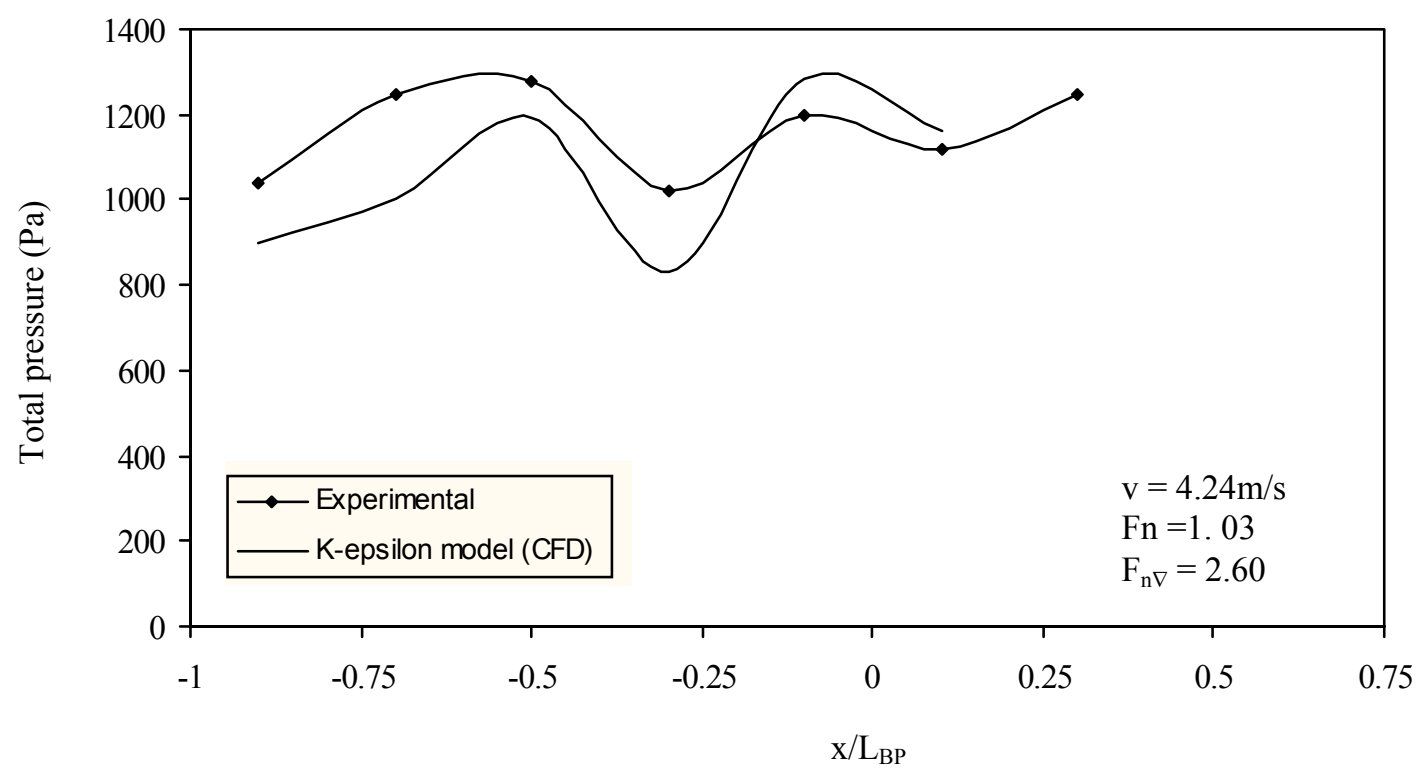

Fig. 21 Comparison of total pressure along the length of the planing hull model for without tunnel case for $\mathrm{L} / \nabla^{1 / 3}=6.50$ ( $25 \%$ breadth from centre line $)$ 